\title{
Synthesis of a Novel Composite Sorbent Coated with Siderite Nanoparticles and its Application for Remediation of Water Contaminated with Congo Red Dye
}

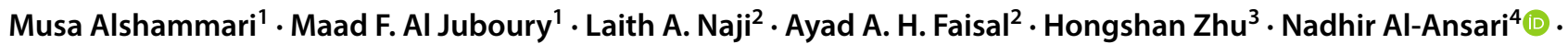 \\ Mu Naushad ${ }^{5}$
}

Received: 23 August 2019 / Revised: 10 December 2019 / Accepted: 30 January 2020 / Published online: 13 February 2020

(c) The Author(s) 2020

\begin{abstract}
Re-use of the byproduct wastes resulting from different municipal and industrial activities in the reclamation of contaminated water is real application for green projects and sustainability concepts. In this direction, the synthesis of composite sorbent from the mixing of waterworks and sewage sludge coated with new nanoparticles named "siderite" (WSSS) is the novelty of this study. These particles can be precipitated from the iron(II) nitrate using waterworks sludge as alkaline agent and source of carbonate. Characterization tests using X-ray diffraction (XRD), scanning electron microscopy (SEM) and energy dispersive spectroscopy (EDS) mapping revealed that the coating process was correctly achieved and siderite nanoparticles were planted on the surface of the composite sorbent. Interaction between Congo Red dye and composite sorbent was evaluated through a set of batch tests under the variation of agitation time, $\mathrm{pH}$ of aqueous solution, and sorbent dosage. The results proved that the prepared sorbent had a high ability in the treatment of water contaminated with Congo Red dye in comparison with previous studies and the maximum adsorption capacity reached to maximum value i.e. $9416 \mathrm{mg} / \mathrm{g}$. The sorption process was governed by electrostatic attractions; however, Sips and Pseudo-second-order models described this process with coefficient of determination greater than 0.99 .
\end{abstract}

\section{Graphic abstract}

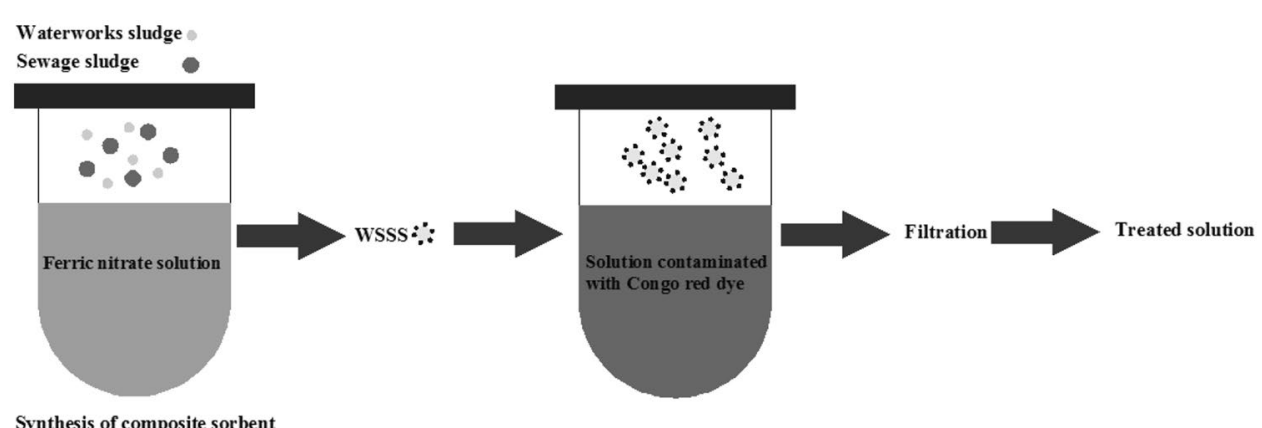

Keywords Siderite nanoparticles $\cdot$ Modified Langmuir model $\cdot$ Coating $\cdot$ Simulation $\cdot$ Sorption

Nadhir Al-Ansari

nadhir.alansari@1tu.se

Extended author information available on the last page of the article

\section{Introduction}

The severe issues concerning anthropogenic water contamination and natural geogenic scarcity of safe water worldwide have become one of the major engineering challenges of the twenty-first century (Naushad et al. 2015a; Mironyuk et al. 
2019). More than 2000 chemical contaminants have been found in wastewater, especially organic pollutants and heavy metal ions (Ali et al. 2020; Tatarchuk et al. 2019; Naushad et al. 2016b). Among them, disposal of organic compounds arising from various industries such as cosmetics, leather, plastics, paper, pharmaceuticals and textiles industries, has attracted much attraction in recent years because of those effluents (Golka et al. 2004; Bao et al. 2011; Sarkar et al. 2018; Naushad et al. 2019) contain a broad types of highly toxic and carcinogenic contaminants (Sahoo et al. 2019). Dyes with aromatic molecular structures are difficult to biodegrade into environmental-friendly substances and quite toxic on the several microorganisms (Sonal et al. 2018; Arslan-Alaton et al. 2009). Congo Red is acidic and anionic dye that can be used as an antifungal therapeutic agent in the field of aquaculture, commercial fish hatchery, and animal husbandry (Sahoo et al. 2019; Ahmad et al. 2007). It has several negative effects on the human beings such as amyloidosis (Frid et al. 2007); accordingly, Europe, United States, Canada and others prohibited the usage of this dye (Gopinathan et al. 2015). Thus, it is of paramount importance to eliminate Congo Red from wastewater.

Until now, many physical and chemical treatment methods have been applied for the removal of dyes from wastewater including coagulation and flocculation (Duan et al. 2010), biological degradation (Gopinathan et al. 2015), adsorption (Jiang et al. 2010; Naushad et al. 2016b), membrane filtration (Gürses et al. 2006), and ultra-chemical filtration (Allègre et al. 2006). Most of these methods have some technical shortcomings such as high cost, secondary pollution, and low processing capacity and have extremely limited application in separation and enrichment of Congo Red dye from contaminated aqueous solutions.

Fortunately, adsorption has been proved to be the most efficient technique compared to other methods due to its simple operation, environmental-friendly, versatile, high efficiency, etc. (Amin 2008). Furthermore, various adsorbents such as activated carbons, natural biosorbent, magnetic porous polymers, and nanofibrous materials have been applied for Congo Red dye removal (Wang and Wang 2007; Safarik et al. 2007; Sahoo et al. 2017, 2019). Nevertheless, these materials cannot fulfill the requirements for Congo Red dye treating due to low adsorption capacity, long diffusion time, or poor structural stability. Thus, it is imperative, but also challenging, to investigate advanced adsorbents that are highly capable of Congo Red dye capture and easy to fabricate (Deb et al. 2019).

Several million tons of waterworks sludge can be produced every year in Europe and this huge quantity can be increased dramatically in the future. The waterworks sludge is considered as "non-hazardous" material according to the EU legislation. This means that the waterworks sludge can be disposed to the sanitary landfills and an increase in the cost of the disposal process was recorded in some countries. Conversely, this sludge was retuned directly to the rivers in other countries and this cause a remarkable increase in the turbidity of the surface water. Another type of solid waste resulted as byproduct from municipal wastewater treatment plants is the "sewage sludge". Due to the presence of phosphorus, nitrogen, and organic substances in the composition of this sludge, it can be used as fertilizer for improvement of soil. Al-Rostomia' a wastewater treatment plant/third extension in Baghdad/Iraq produces large quantities of sewage sludge which is collected in fourteen units of drying beds with apparent volume not less than $850 \mathrm{~m}^{3}$ for each unit and these quantities may be banished to the ecosystem. Hence, water companies and other authorities directed their efforts to find the cheaper solutions for minimizing the problems accompanied with the elimination of (waterworks and sewage) sludge (Basibuyuk and Kalat 2004).

Accordingly, the novelty of the present study can be summarized as follows; (1) the use of the described byproducts as sorbents could be a good solution for huge quantities of these wastes in terms of sustainable development and green projects, as well as a means of cutting disposal costs, (2) the manufacturing of nanoparticles named scientifically as "siderite" from waterworks sludge as alkaline agent with aid of Iron(II) nitrate by the new preparation method which was not adopted previously in the related topics and, (3) producing reactive material with new additional sites by planted "siderite" onto the waterworks-sewage sludge. The ability of composite material in the treatment of the wastewater was evaluated using Congo Red as target contaminant.

Herein, the waterworks sludge modified by $\mathrm{Fe}^{2+}$ composite was synthesized by a simple precipitation method for Congo Red removal. SEM, XRD, and EDS were applied to systematically analyze the morphologies and physicochemical properties. The influencing various factors, including temperature, contact time, solid content, $\mathrm{pH}$ value, ionic strength, and starting concentration, for Congo Red removal were investigated by batch experiments. Furthermore, the mechanism between WSSS and Congo Red is also studied and this paper offered new horizons for Congo Red removal from contaminated water and extended the applications of the WSSS adsorbents for environmental pollution control.

\section{Material and Methods}

\section{Sorbent and Contaminant}

Al-Wehda water treatment plant (WTP) in the Baghdad city, capital of Iraq was the source of the waterworks sludge used in the present study. The raw water entered to this plant always purified using alum salts and this means that the aluminum is definitely present in the composition of this sludge. Air was used to dry the collected sludge for three 
days and, then, grinded to obtain the mesh size ranged from 1 to $0.063 \mathrm{~mm}$ with mean diameter of $0.25 \mathrm{~mm}$ (Mathews and Zayas 1989). Also, sewage sludge was collected from Al-Rostomia' a wastewater treatment plant/Baghdad/Iraq and dried at the atmospheric temperature for 5 days. Distilled water was used in the washing of the sewage sludge; then, sieving to obtain the same mesh size range as in the waterworks sludge and, finally, dried it at $70{ }^{\circ} \mathrm{C}$ for $6 \mathrm{~h}$. Concentrations of heavy metals were measured in the solid phase of sewage sludge and the values are listed in Table 1 in comparison with the acceptable limits of the New Dutch list. It seems that this sludge tends to retain the heavy metals, thereby eliminating the environmental pollution (Doke et al. 2012; Simantiraki et al. 2013).

Congo Red (Central Drug House (P) Ltd.) was taken as a target contaminant for representation the aqueous solution contaminated with organic compound. To simulate the water's Congo Red contamination, a solution of Congo Red was prepared with concentration of $1000 \mathrm{mg} / \mathrm{L}$ and it was kept at room temperature. Successive dilutions for this solution were adopted to prepare the required concentration of Congo Red and $0.1 \mathrm{M} \mathrm{HCl}$ (or $0.1 \mathrm{M} \mathrm{NaOH}$ ) was added to adjust the $\mathrm{pH}$ of the solution.

\section{Preparation of Composite Sorbent}

A modified precipitation method was adopted where different percentages of waterworks sludge/sewage sludge were added to $50 \mathrm{~mL}$ of solution containing $2 \mathrm{~g} \mathrm{Fe}\left(\mathrm{NO}_{3}\right)_{2}$. To specify the best percentage of these two sludge, the mixture was stirred for $180 \mathrm{~min}$ using orbital shaker, dried at $105^{\circ} \mathrm{C}$ for $4 \mathrm{~h}$ and, then, washed with de-ionized water to remove unattached nanoparticle. After that, the best percentage was added to different concentrations of $\mathrm{Fe}\left(\mathrm{NO}_{3}\right)_{2}$ solution and the mixture was stirred and dried in the same procedure mentioned previously. In the final step, the solid particles were dried at $105{ }^{\circ} \mathrm{C}$ for $24 \mathrm{~h}$ and stored in a capped bottle for further use (Phuengprasop et al. 2011). The adsorption capacity for Congo Red dye using the composite sorbents coated with nanoparticles of siderite prepared under different preparation conditions was the main criterion used in

Table 1 Measured concentrations of heavy metals in the solid phase of the sewage sludge

\begin{tabular}{lll}
\hline Metal & Concentration $(\mathrm{mg} / \mathrm{kg})$ & $\begin{array}{l}\text { New Dutch limits } \\
\text { (Doke et al. 2012) }\end{array}$ \\
\hline Cadmium & $<0.5$ & 12 \\
Copper & 100 & 190 \\
Lead & 32 & 85 \\
Nickel & 30 & 210 \\
Zinc & 450 & 720 \\
\hline
\end{tabular}

the evaluation of the best sorbent. Surface morphology of waterworks sludge, sewage sludge, and prepared composite sorbent coated with siderite nanoparticles was examined by scanning electron microscopy (SEM) equipped with an EDS (XFlash 5010; Bruker AXS Microanalysis, Berlin, Germany). Digital mapping can be generated from EDS analysis for adopted sorbents where the brightness of the images is correlated with the intensity of the pixels for the elements in the sample. Crystalline structures of different sorbents described previously were examined via X-ray diffraction (XRD) analysis at wavelength $(\lambda)$ of $1.789 \AA$ (Siemens X-ray diffractometer, D8 Advance, Bruker, Germany) in Germany Laboratory/Department of Geology/University of Baghdad.

\section{Sorption Tests}

Here, $250 \mathrm{~mL}$ conical-flasks were taken and $50 \mathrm{~mL}$ of aqueous solution contaminated with $50 \mathrm{mg} / \mathrm{L}$ of Congo Red dye was added to each flask. Different dosages of sludge ranged from 0.01 to $0.3 \mathrm{~g}$ were added to each flask and the mixture was kept stirred on an agitation speed equal to $200 \mathrm{rpm}$ using orbital shaker (Edmund Buhler SM25, German). To separate solid phase from liquid phase, treated aqueous solution was filtered using filter paper type (JIAO JIE 102) and certain volume $(\approx 10 \mathrm{~mL})$ of filtered solution was analyzed to measure the concentration of Congo Red using an ultraviolet-visible (UV) spectrophotometer (Shimadzu Model: UV/VIS-1650) at the maximum absorption wavelength of $497 \mathrm{~nm}$. The experiments for specifying the equilibrium time were implemented by withdrawing the periodic samples through the time period not exceeding $300 \mathrm{~min}$. Additional tests were conducted to study the effect of initial $\mathrm{pH}$ in the range of (3-9.6) on the removal efficiency of Congo Red with constant concentration of Congo Red $(1000 \mathrm{mg} / \mathrm{L})$. The removal efficiency of the contaminant was calculated as follows:

$R=\frac{\left(C_{o}-C_{e}\right)}{C_{o}} \times 100$,

where $C_{o}$ and $C_{e}$ are the initial and equilibrium concentrations of Congo Red dye (mg/L). The amount of this contaminant retained in the sorbent material, $q_{e}(\mathrm{mg} / \mathrm{g})$, was determined as:

$q_{e}=\left(C_{o}-C_{e}\right) \frac{V}{m}$

where $m$ is the sorbent quantity that added to the flask (g) and $V$ is the volume of aqueous solution (L). 


\section{Sorption Models}

The sorption models describe the specific relation between sorbed quantity of dye onto solid phase $\left(q_{e}\right)$ and the concentration of dye in the bulk solution $\left(C_{e}\right)$ at equilibrium state (Zheng et al. 2009). This relation can be represented by Freundlich, Langmuir and Sips models (Table 2) and these models are plotted at constant values of $\mathrm{pH}$ and temperature. In addition, it is important to predict the rate at which dye removed from aqueous solutions to design appropriate sorption treatment processes (Puranik et al. 1999), accordingly, the sorption kinetic models (Lagergren 1989; Ho and McKay 1999; Ho et al. 2002; Hamdaoui and Naffrechoux 2007; Gheju and Miulescu 2007; Foo and Hameed 2010) mentioned in the Table 2 can be used to find this rate.

\section{Results and Discussion}

\section{Composite Sorbent}

Composite sorbent adopted in the present study is a mixture of waterworks sludge and sewage sludge treated with different amounts of Iron(II) nitrate to achieve the required coating by precipitation of the nanoparticle materials. The maximum sorption capacities were determined due to the interaction of Congo Red dye with different percentages of composite sorbent under various quantities of Iron(II) nitrate as shown in Fig. 1. It is clear that the increase of waterworks sludge amount from 0 to $0.75 \mathrm{~g} / \mathrm{g}$ caused a significant increase in the sorption capacity. This might be due to the dissolution of calcium carbonate (the main constituent of waterworks sludge) in the aqueous solution where the calcium ions increased the $\mathrm{pH}$ and, consequently, this led to precipitate a new nanoparticles named as siderite on the composite sorbent. The reactions governing the precipitation process is described by the following equations:

$\mathrm{CaCO}_{3} \rightarrow \mathrm{Ca}+\mathrm{CO}_{3}$,

$\mathrm{Fe}+\mathrm{CO}_{3} \rightarrow \mathrm{FeCO}_{3}$

When the waterworks sludge quantity was equal to $0.75 \mathrm{~g}$ of composite sorbent, the coating with siderite increased the sorption capacity up to $24.7 \mathrm{mg} / \mathrm{g}$ in comparison with capacity value that was equal to $19.5 \mathrm{mg} / \mathrm{g}$ for composite sorbent consisted of sewage sludge only. This means that $0.75 \mathrm{~g}$ waterworks sludge mixed with $0.25 \mathrm{~g}$ sewage sludge represented the best mixture used to prepare a composite sorbent coated with siderite nanoparticles. To specify the better quantity of Iron(II) nitrate that used in the coating process, the best mixture of composite sorbent was treated with different amounts of this nitrate in the range of $(1-5 \mathrm{~g})$ added to $50 \mathrm{~mL}$ of aqueous solution. Figure $1 \mathrm{~b}$ shows the effect of Iron(II) nitrate dosage on the sorption capacity of Congo Red on the coated composite sorbent. The results certified that the increase of Iron(II) nitrate from 1 to $2 \mathrm{~g}$ caused a significant increment in the sorption capacity and this capacity was decreased beyond $2 \mathrm{~g}$. This reduction may be due to the saturation of surface area on the composite sorbent with siderite particles and excessive amount of these particles (i.e. uncoated siderite) would be removed by washing at the end of preparation process, therefore, $2 \mathrm{~g}$ of Iron(II) nitrate will be adopted coating.
Table 2 Isotherm and kinetic models used to describe the sorption data

\begin{tabular}{lll}
\hline Model & Formula $^{\mathrm{a}}$ & References \\
\hline Isotherm & $q_{e}=K_{F} C_{e}^{1 / n}$ & \\
Freundlich & $q_{e}=\frac{q_{\max } b C_{e}}{1+b C_{e}}$ & Deb et al. (2019) and Ho et al. (2002) \\
Langmuir & $q_{e}=\frac{K_{s} C_{s}^{\beta_{s}}}{a_{s} C_{e}^{\beta_{s}}+1}$ & Foo and Hameed (2010) \\
Sips & & Hamdaoui and Naffrechoux (2007) \\
Kinetic & $q_{t}=q_{e}\left[1-\exp \left(-k_{1} t\right)\right]$ & \\
Pseudo first order & $q_{t}=k_{2} q_{e}^{2} t /\left(1+k_{2} q_{e} t\right)$ & Lagergren (1989) \\
Pseudo second order & Ho and McKay (1999) \\
\hline
\end{tabular}

${ }^{\text {a }} K_{F}$ is related with the adsorption capacity of the sorbent, and $n$ is the intensity of sorption; $q_{\max }$ is the maximum adsorption capacity $(\mathrm{mg} / \mathrm{g})$, and $b$ is the affinity between the dye and sorbent; $K_{s}, a_{s}$ and $\beta_{\mathrm{s}}$ are the constants; $k_{l}$ is the equilibrium rate constant of pseudo first order sorption $(1 / \mathrm{min}), k_{2}$ is the rate constant of sorption (g/mg min), $q_{e}$ is the quantity of dye sorbed at equilibrium $(\mathrm{mg} / \mathrm{g})$, and $q_{t}$ is the quantity of dye sorbed at time $t(\mathrm{mg} / \mathrm{g})$ 
Fig. 1 Sorption capacity of Congo Red dye onto composite sorbent under the effects of different a ratios of waterworks sludge mixed with sewage sludge and $\mathbf{b}$ dosages of ferric nitrate
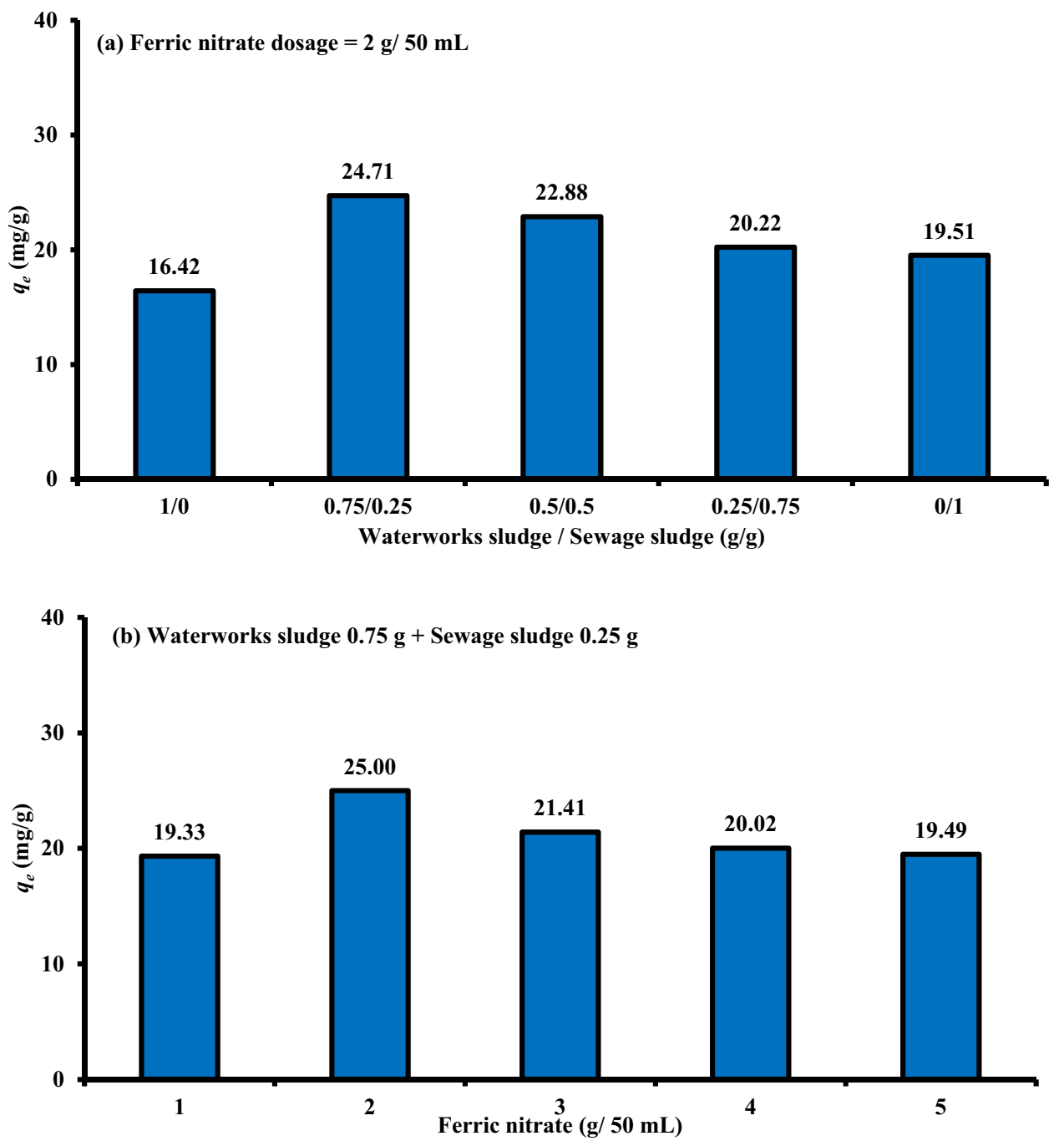

\section{Characterization of Different Sorbents}

Figure 2 shows the crystalline structures for waterworks sludge, sewage sludge, and prepared composite sorbent coated with siderite nanoparticles through plotting the patterns of the X-ray diffraction (XRD) analysis. It is clear that the silica oxide, calcite, and iron oxide are the main components of waterworks sludge, however, the hydroxyapatite and iron oxide can be recognized in the composition of the sewage sludge. Also, this figure certifies that the coating of the prepared composite sorbent with siderite nanoparticles is achieved in the efficient manner depended on the peaks of $(24.8,32.1$ and 38.4) with Miller planes of $(012,104$, and 110).

Figure 3 elucidates the morphology of waterworks sludge, sewage sludge, and prepared composite sorbent coated with siderite nanoparticles using SEM images. It seems that the shape of these sorbents before interaction with Congo Red dye is irregular with evidence pores, however, nanoparticles of the siderite can be attached on the surface of composite sorbent after sorption process. Multi-elemental EDS mapping images for same sorbents before and after sorption process signified the presence of $\mathrm{C}, \mathrm{O}, \mathrm{Mg}, \mathrm{Na}, \mathrm{Al}, \mathrm{Fe}, \mathrm{N}, \mathrm{Ca}$, $\mathrm{Si}, \mathrm{Ti}, \mathrm{N}, \mathrm{S}$ and $\mathrm{P}$ constituents as shown in Fig. 4. The maps corresponding for these peaks revealed that there are bright spots for the calcified area with heterogeneous distribution of the elements in the view of the cross-section. This figure illustrates the increase of $\mathrm{Fe}$ intensities in the green dotted areas for composite sorbent and this related with the presence of siderite nanoparticles or, in other words, the success of coating process. In addition, the increase of $S$ intensities in the pink dotted areas after sorption process means the removal of Congo Red dye on the coated sorbent.

\section{Contact Time}

The contact time required to achieve the equilibrium status must be specified and the effect of contact time on the removal of Congo Red dye using 0.05, 0.08, 0.1, 0.3 and $0.5 \mathrm{~g}$ of composite sorbent added to $50 \mathrm{~mL}$ of aqueous 
Fig. 2 XRD patterns of the waterworks sludge, sewage sludge, and composite sorbent before sorption process

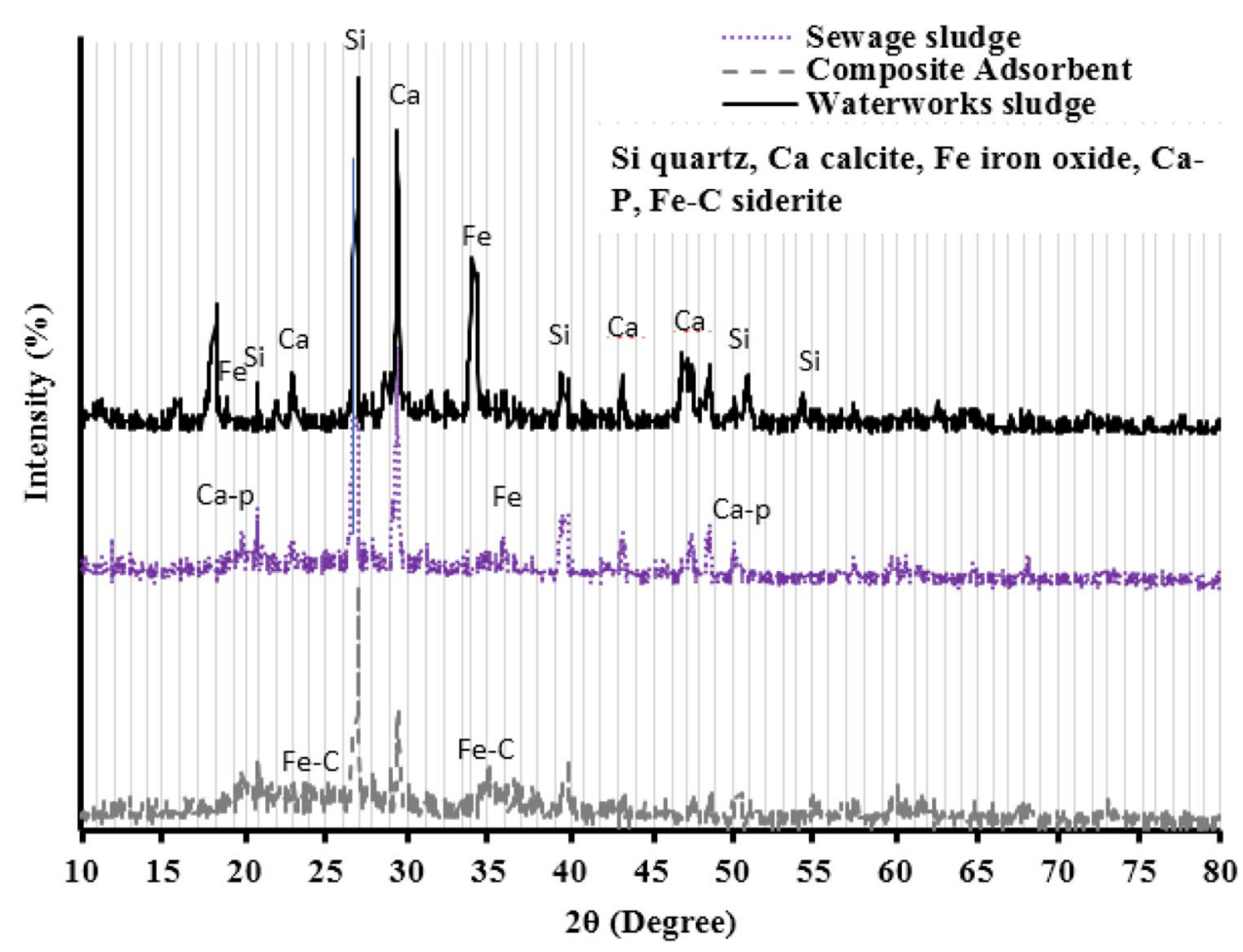

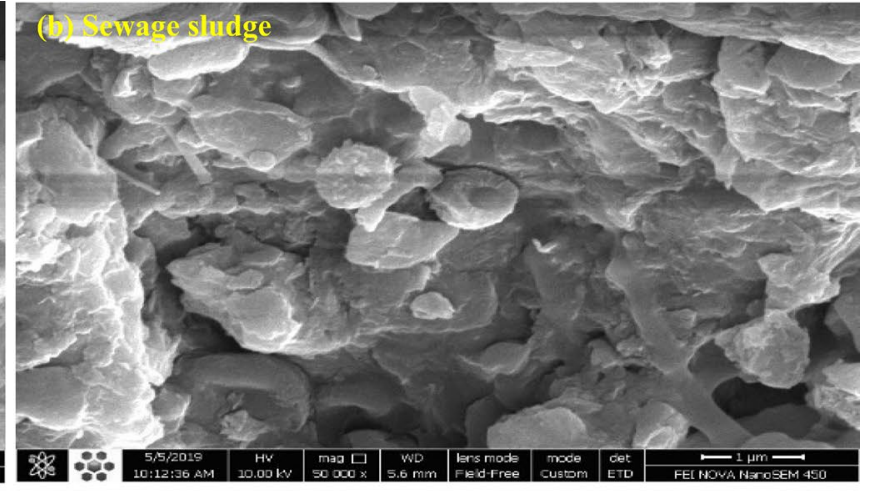
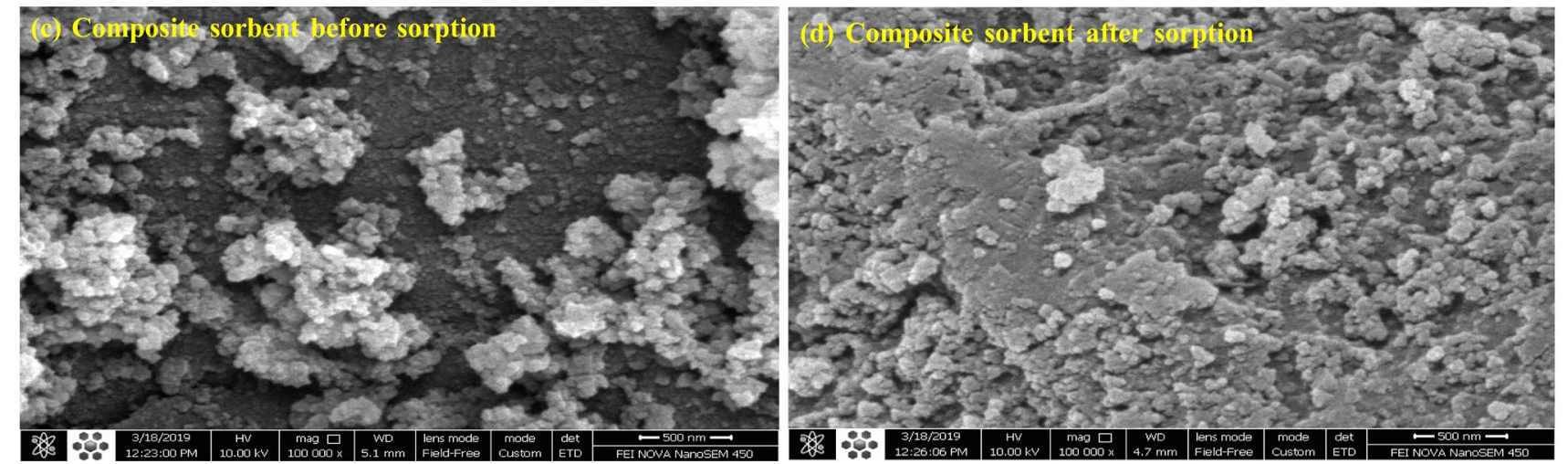

Fig. 3 Scanning electron microscopy (SEM) images of waterworks sludge, sewage sludge, and composite sorbent used in the present study 

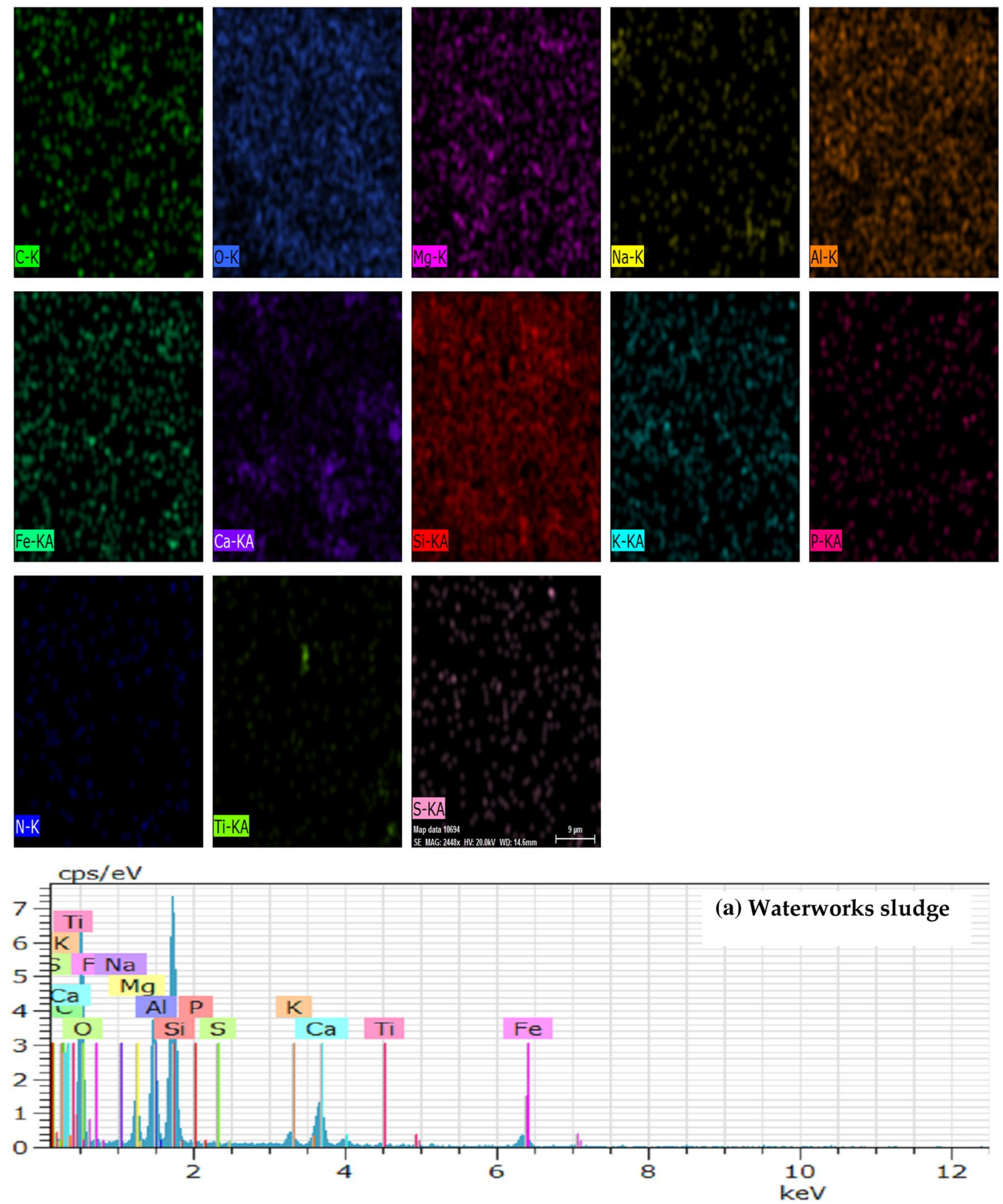

Fig. 4 EDS and EDS mapping of waterworks sludge, sewage sludge, and composite sorbent used in the present study

solution at room temperature and initial concentration of $50 \mathrm{mg} / \mathrm{L}$ is plotted in Fig. 5a. This figure demonstrates that the increase of contact time has a positive effect on the removal percentage of the target contaminant. In the initial stages, the sorption rate was incremental increase and, afterwards, it can be gradually slowed. This reduction in the rate of the sorption definitely related with decrease of the vacant sites on the surface of the sorbent. The kinetic data shows that $71 \%$ of Congo Red dye was removed mainly at $5 \mathrm{~min}$ with sorbent dosage of $0.05 \mathrm{~g} / 50 \mathrm{~mL}$ and there was no significant change in residual concentrations after this equilibrium time up to $270 \mathrm{~min}$. 

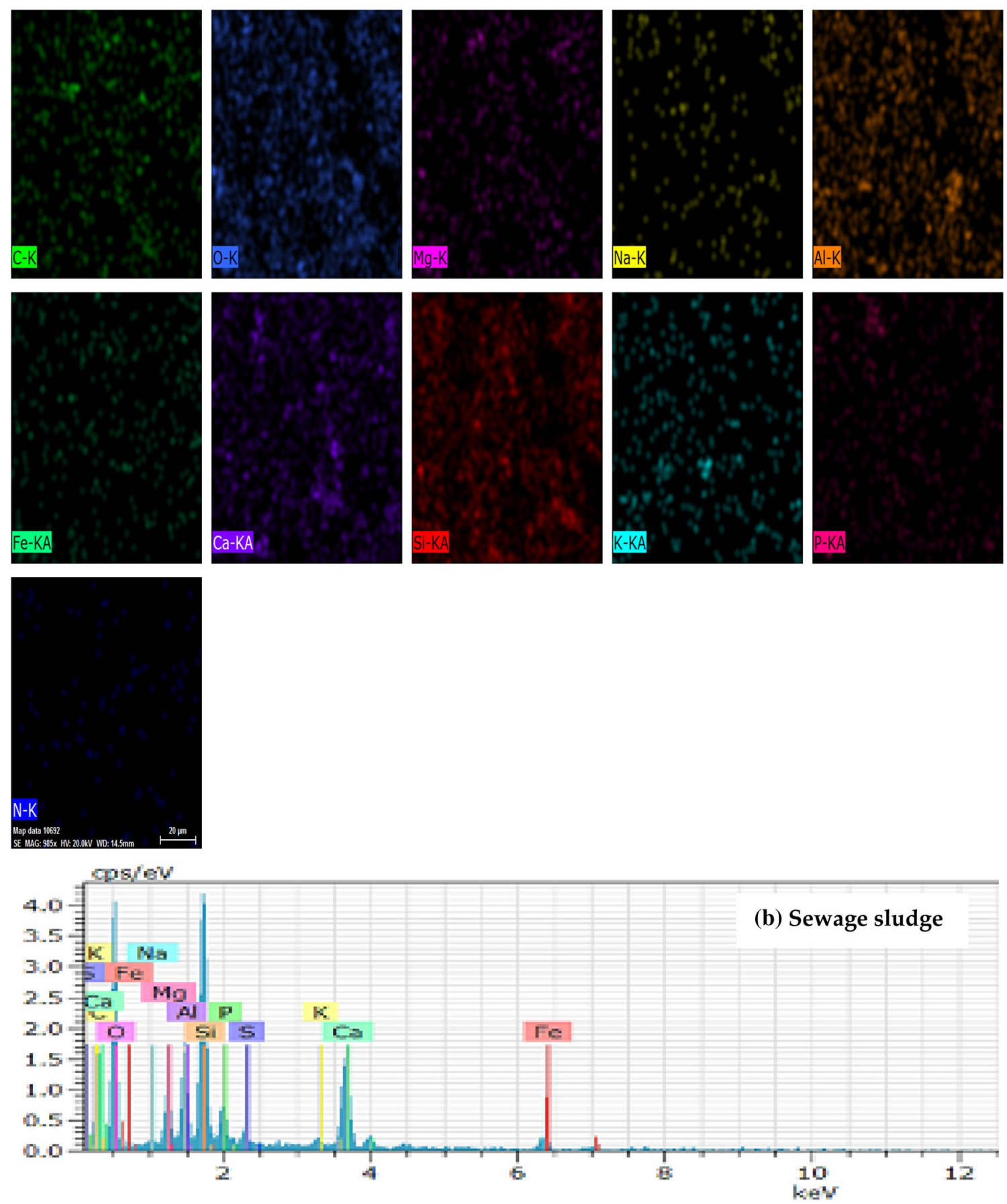

Fig. 4 (continued)

\section{Initial pH of Contaminated Water}

The effect of $\mathrm{pH}$ on the removal of Congo Red dye from aqueous solution was studied in the range from 3 to 9.6 (Fig. 5b). At pH of 7, the color of the dye was red and it remains the same at alkaline solution (i.e. $\mathrm{pH}>7$ ); however, dark blue color was recognized for acidic solution (i.e. $\mathrm{pH}<5$ ). Also, it is observed that the solubility of dye was decreased at $\mathrm{pH}$ less than 2 and, consequently, the lowest value of $\mathrm{pH}$ adopted in the tests was 3.1 (Sahoo et al. 2019). The maximum removal efficiency of Congo Red dye was recorded at $\mathrm{pH}$ of 3.1 with value of $100 \%$ and this removal was approximately remained constant until $\mathrm{pH}$ equal to 6 , however, gradually decrease in the removal efficiency was recognized with increase of initial $\mathrm{pH}$ to reach the value of $50 \%$ at $\mathrm{pH}$ equal to 9.6 . For $\mathrm{pH}$ equal to 

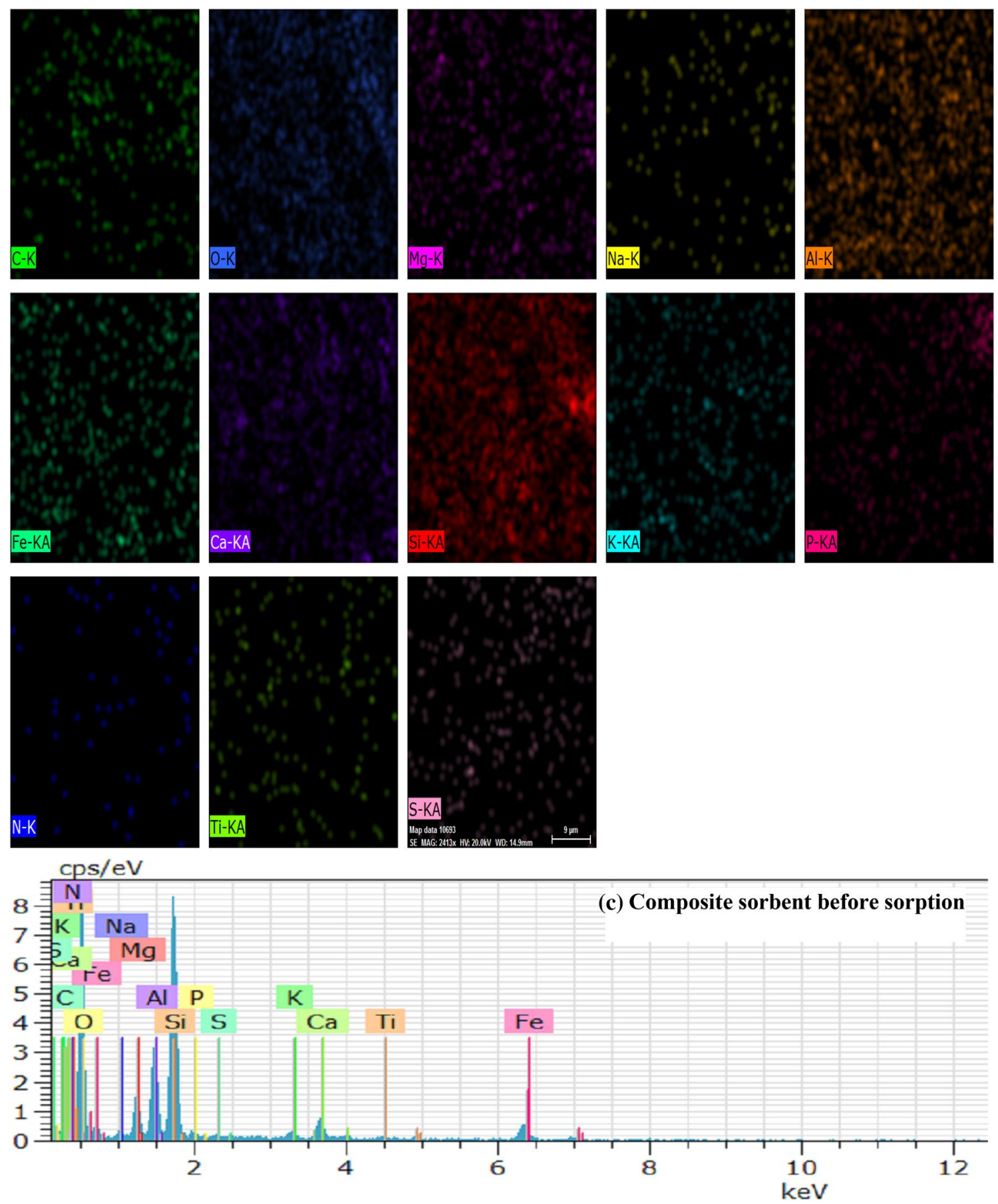

Fig. 4 (continued)

3.1, a strong interaction can be generated between anionic dye and positive charge surface of sorbent due to electrostatic attraction. Conversely, electrostatic repulsion can be appeared at higher $\mathrm{pH}$ between anionic dye and the negative charges on the surface sites. Also, a competition between excess of $\mathrm{OH}^{-}$ions and anionic dye on the bonding sites can be explained the decrease of removal efficiency in the basic solution. The same results were recorded for the sorption of Congo Red dye on dialdehyde cellulose-cross linked cellulose-chitosan foam (Kim et al. 2019), graphene oxide-NiFe layered double hydroxide (Zheng et al. 2019) and amine functionalized magnetic iron oxide nanoparticles (Sahoo et al. 2019). 

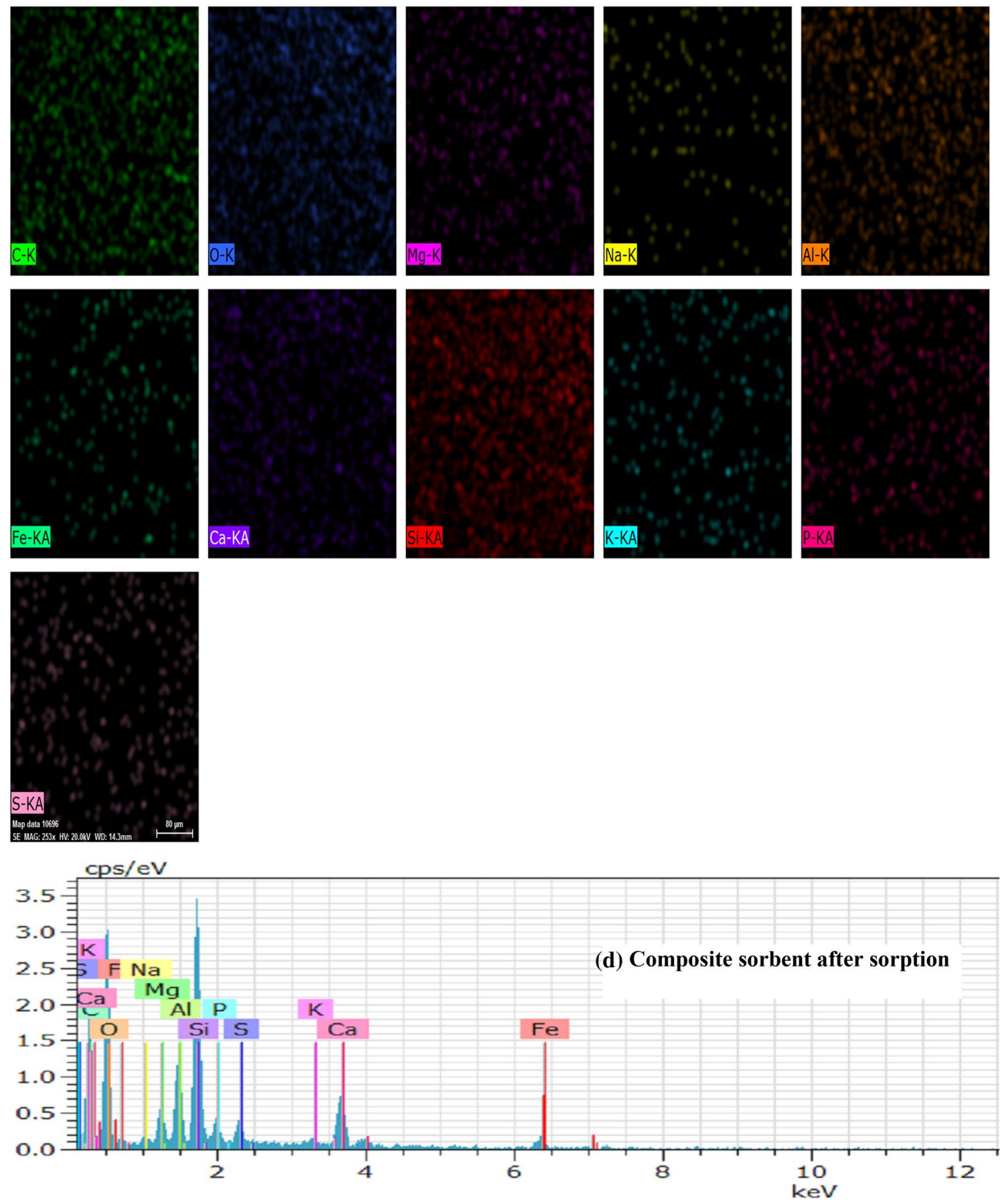

Fig. 4 (continued)

\section{Dosage of Composite Sorbent}

Sorbent dosage significantly affected the removal efficiency of contaminant species. This parameter was investigated at room temperature by changing the amounts of composite sorbent from 0.01 to $0.1 \mathrm{~g}$ (Fig. 5c) added to
$50 \mathrm{~mL}$ of contaminated water where the dye concentration of $1000 \mathrm{mg} / \mathrm{L}, \mathrm{pH}$ of 3 and equilibrium time of $3 \mathrm{~h}$. It is clear that the increasing of sorbent dosage enhanced the dye removal efficiency until it reached the steady state trend, however, this will be accompanied by a significant reduction in the sorption capacity. 
Fig. 5 The effect of various operation conditions on the sorption of Congo Red dye onto the prepared composite sorbent

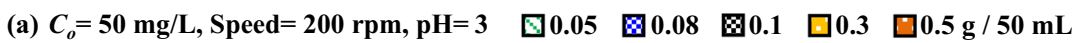

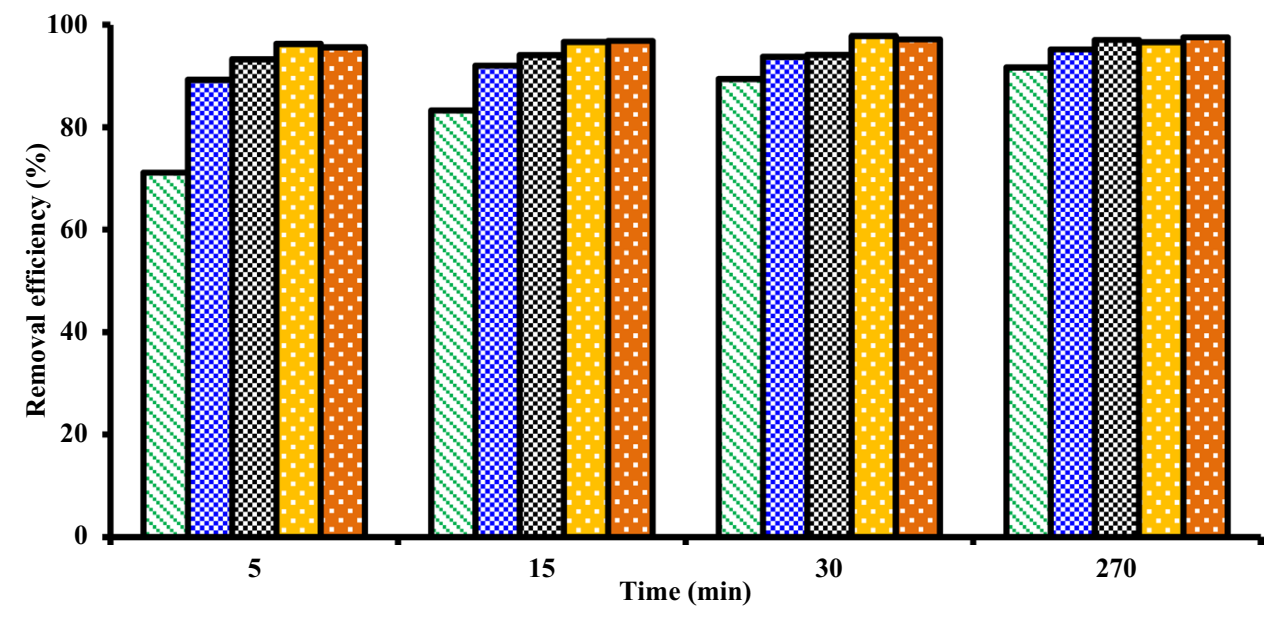

(b) Time $=3 \mathrm{hr}, C_{o}=1000 \mathrm{mg} / \mathrm{L}$, Speed $=200 \mathrm{rpm}$, Dosage $=0.06 \mathrm{mg} / 50 \mathrm{~mL}$

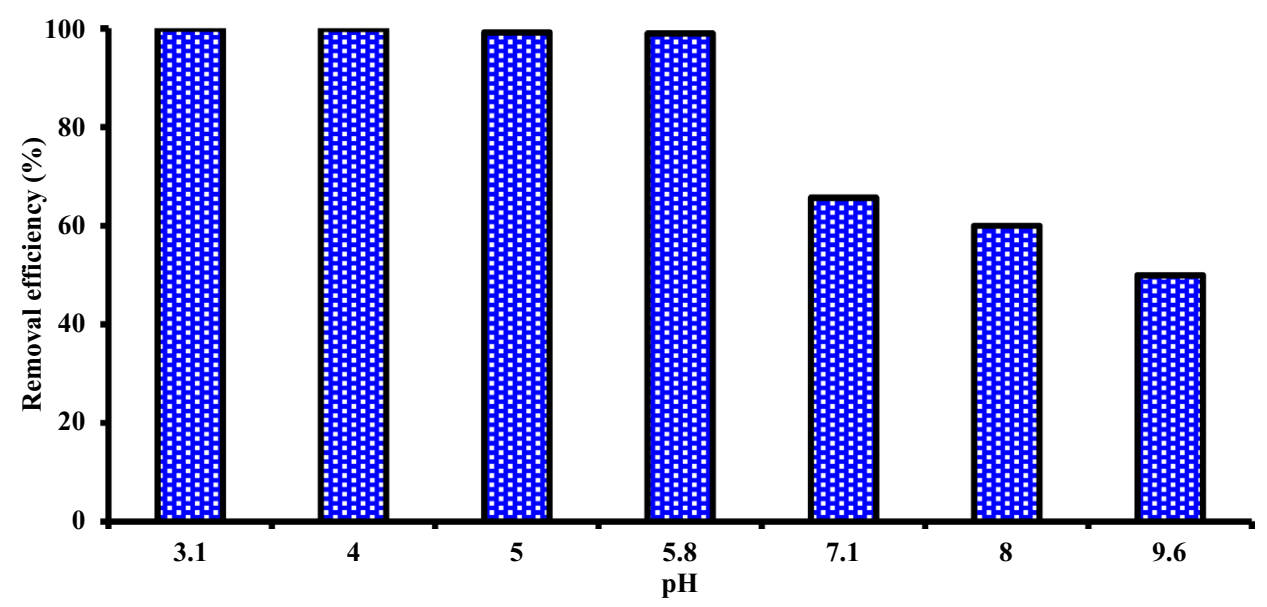

(c) Time $=3 \mathrm{hr}, C_{o}=1000 \mathrm{mg} / \mathrm{L}$, Speed $=200 \mathrm{rpm}, \mathrm{pH}=3$

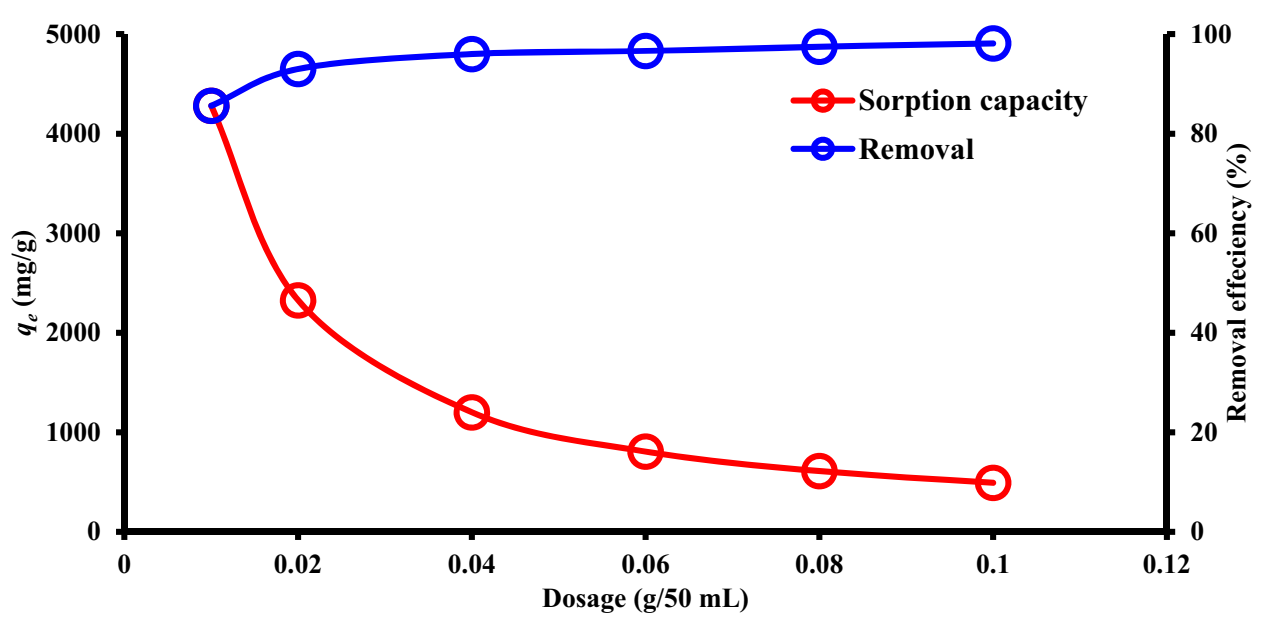

\section{Isotherm and Kinetic Models}

Freundlich, Langmuir and Sips isotherms are shown graphically in Fig. 6 where their constants are listed in Table 2 which were determined by fitting with measured data using "Solver" option for nonlinear expressions in Excel 2016. It is clear that all models presented a good representation for experimental measurements, however, Sips model was more 
Fig. 6 Isotherms and kinetics models used in the present study
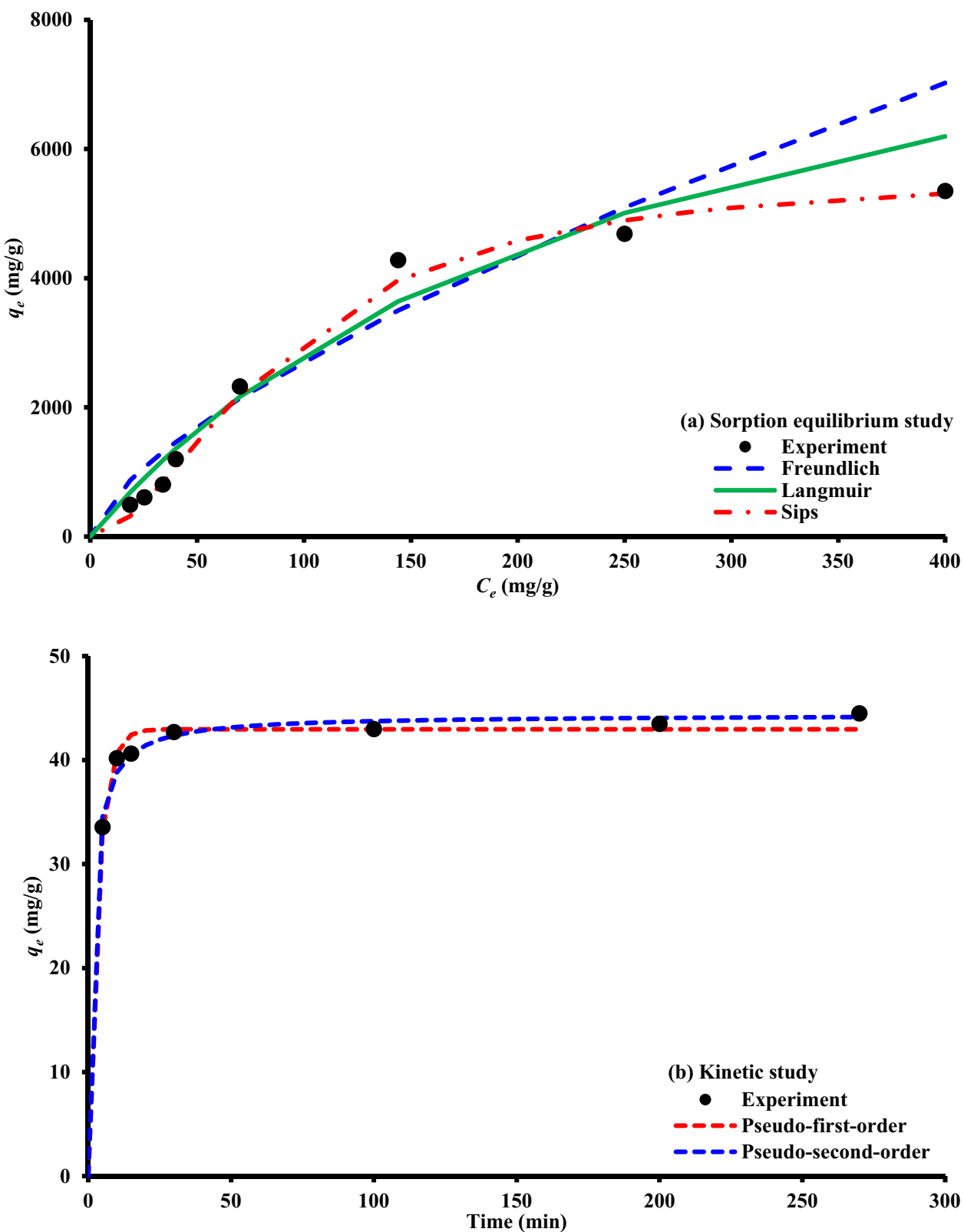

representative for fitted data from other models because the value of determination coefficient $\left(R^{2}\right)$ equal to 0.997 as given in Table 3. The application of Sips model means that the sorption process was heterogeneous. The most important character of the prepared composite sorbent was its high maximum sorption capacity which was $9416 \mathrm{mg} / \mathrm{g}$ as illustrated in Table 3 . This value was greater than the findings of the previous studies (Yang et al. 2015; Zheng et al. 2017, 2019; Zhao et al. 2017; Bao et al. 2019) as shown in the Table 4 and, accordingly, the present composite sorbent coated with siderite nanoparticles manufactured from byproduct wastes can be used as substitute option for many industrial sorbents. In addition, the nonlinear fits for the kinetics results using kinetic models proved that the Pseudo second order model exhibits higher $R^{2}$ and lower value of sum of squared errors (SSE) in comparison with the Pseudo first order model (Fig. 6 and Table 3). This specifies that the sorption kinetics process follows Pseudo second order and this process was governed by chemisorption mechanism which involved valence forces between dye anion and composite sorbent.

\section{Possible Mechanisms}

Removal of Congo Red dye could be probably achieved by two possible mechanisms namely; (1) electrostatic interaction between the protonated groups of nanoparticle or organic functional groups of sewage sludge and acidic 
Table 3 Constants of the isotherm and kinetic models specified from non-linear regression analysis for Congo Red dye sorption onto composite sorbent

\begin{tabular}{ll}
\hline Constants of models & Value \\
\hline Freundlich & \\
$K_{F}$ & 118.17 \\
$n$ & 1.467 \\
$R^{2}$ & 0.937 \\
Langmuir & \\
$q_{\text {max }}$ & 9416 \\
$b$ & 0.0045 \\
$R^{2}$ & 0.968 \\
Sips & \\
$K_{s}$ & 1.722 \\
$\beta_{\mathrm{s}}$ & 1.7995 \\
$a_{s}$ & 0.0003 \\
$R^{2}$ & 0.997 \\
Pseudo-first-order & \\
$k_{l}$ & 0.293 \\
$q_{e}$ & 42.967 \\
SSE & 6.4615 \\
$R^{2}$ & 0.922 \\
Pseudo-second-order & \\
$k_{2}$ & 0.0158 \\
$q_{e}$ & 44.369 \\
SSE & 3.9321 \\
$R^{2}$ & 0.952 \\
\hline
\end{tabular}

Table 4 Maximum sorption capacities for prepared composite sorbent in comparison with different reactive materials adopted from previous studies for Congo Red dye as target contaminant

\begin{tabular}{lll}
\hline Material & $q_{\max }(\mathrm{mg} / \mathrm{g})$ & References \\
\hline Composite sorbent & 9416 & Present study \\
3D hierarchical GO-NiFe LDH & 489 & Zheng et al. (2019) \\
Flower-Like NiO microspheres & 534.8 & Zheng et al. (2017) \\
Core-shell Fe $(\mathrm{OH})_{3} @$ Cellulose & 689.65 & Zhao et al. (2017) \\
$\mathrm{NiCo}_{2} \mathrm{O}_{4}$ nanosheets & 961.5 & Bao et al. (2019) \\
$\mathrm{CNT} / \mathrm{Mg}(\mathrm{Al}) \mathrm{O}$ nanocomposites & 1250 & Yang et al. (2015) \\
\hline
\end{tabular}

dye and (2) the chemical reaction between the dye and the composite sorbent. At low $\mathrm{pH}$, high electrostatic attraction exists between the anionic dye and positively charged surface of the solid particles. With increase of $\mathrm{pH}$, an increase in the number of negatively charged sites can be observed and, accordingly, these sites don't favor the adsorption of dye anions due to the electrostatic repulsion. Also, lower adsorption of Congo Red dye at alkaline system may be due to the presence of excess hydroxides ions competing with the dye anions for the adsorption sites. However, significant adsorption of the anionic dye on the adsorbent still occurred at alkaline $\mathrm{pH}$. This suggested that the second mechanism, i.e. chemisorption, might be operative. A similar trend was observed for the adsorption of Congo Red on materials like biogas residual slurry as well as waste orange peel and banana pith (Namasivayam and Kavitha 2002; Bhowmik et al. 2018a, b).

\section{Regeneration Study}

Desorption study aims to express the nature of adsorption, ability for recycling of the spent adsorbent with recovery of Congo Red dye. The desorption process was performed by mixing of spent adsorbent with $0.01 \mathrm{~mol} / \mathrm{L}$ of $\mathrm{NaOH}$ solution and the desorption efficiency was found greater than 96\%. This means that Congo Red dye could be desorbed from the loaded adsorbent by changing the $\mathrm{pH}$ of the solution to the alkaline range and $\mathrm{NaOH}$ solution has higher desorption efficiency.

\section{Conclusions}

The unique property of this study was to synthesize a new composite sorbent consisted of the mixture of byproduct wastes (waterworks sludge and sewage sludge) coated with siderite nanoparticles and the results proved that this sorbent had an excellent ability in the removal of Congo Red dye from simulated wastewater. The siderite nanoparticles were prepared from the precipitation of Iron(II) nitrate using waterworks sludge as alkaline agent and source of carbonate. Characterization tests such as XRD, SEM, and EDS mapping elucidated that the coating process led to produce the efficient sorbent with maximum sorption capacity arrived to $9416 \mathrm{mg} / \mathrm{g}$ and this can be attributed to nanoparticles (i.e. new sites) planted on the composite material. In comparison with Freundlich and Langmuir isotherm models, the sorption of Congo Red dye onto the prepared composite sorbent was described well by the Sips heterogeneous model with $R^{2}$ not less than 0.997 , while the sorption kinetic was represented by Pseudo-second-order expression. The authors recommend to study the ability of using the prepared composite sorbent in the future studies for fixed bed column or for the permeable reactive barrier technology to restriction and containment of the contaminant front and finding the longevity of the bed that satisfied the environmental regulations.

Acknowledgements Open access funding provided by Lulea University of Technology. We would like to gratefully acknowledge the technical support of Environmental Engineering Department/University of Baghdad, College of Engineering, University of Kerbala and Lulea University of Technology provided during the present work. One of the authors (Mu. Naushad) is grateful to the Researchers Supporting Project number (RSP-2019/8), King Saud University, Riyadh, Saudi Arabia for the support. 
Open Access This article is licensed under a Creative Commons Attribution 4.0 International License, which permits use, sharing, adaptation, distribution and reproduction in any medium or format, as long as you give appropriate credit to the original author(s) and the source, provide a link to the Creative Commons licence, and indicate if changes were made. The images or other third party material in this article are included in the article's Creative Commons licence, unless indicated otherwise in a credit line to the material. If material is not included in the article's Creative Commons licence and your intended use is not permitted by statutory regulation or exceeds the permitted use, you will need to obtain permission directly from the copyright holder. To view a copy of this licence, visit http://creativecommons.org/licenses/by/4.0/.

\section{References}

Abd Ali ZT, Naji LA, Almuktar SAAAN, Faisal AAH, Abed SN, Scholz M, Naushad M, Ahamad T (2020) Predominant mechanisms for the removal of nickel metal ion from aqueous solution using cement kiln dust. J Water Process Eng 33:101033. https:// doi.org/10.1016/j.jwpe.2019.101033

Ahmad AA, Hameed BH, Aziz N (2007) Adsorption of direct dye on palm ash: kinetic and equilibrium modeling. J Hazard Mater 141(6):70-76

Allègre C, Moulin P, Maisseu M, Charbit F (2006) Treatment and reuse of reactive dyeing effluents. J Membr Sci 269(1-2):15-34

Amin NK (2008) Removal of reactive dye from aqueous solutions by adsorption onto activated carbons prepared from sugarcane bagasse pith. Desalination 223(1-3):152-161

Arslan-Alaton I, Tureli G, Olmez-Hanci T (2009) Treatment of azo dye production wastewaters using photo-fenton-like advanced oxidation processes: optimization by response surface methodology. J Photochem Photobiol A 202(2-3):142-153

Bao N, Li Y, Wei Z, Yin G, Niu J (2011) Adsorption of dyes on hierarchical mesoporous $\mathrm{TiO}_{2}$ fibers and its enhanced photocatalytic properties. J Phys Chem C 115(13):5708-5719

Bao Y, Qin M, Yu Y, Zhang L, Wu H (2019) Facile fabrication of porous $\mathrm{NiCo}_{2} \mathrm{O}_{4}$ nanosheets with high adsorption performance toward Congo Red. J Phys Chem Solids 124:289-295

Basibuyuk M, Kalat DG (2004) The use of waterworks sludge for the treatment of vegetable oil refinery industry wastewater. Environ Technol (United Kingdom) 25(3):373-380

Bhowmik KL, Deb K, Bera A, Debnath A, Saha B (2018a) Interaction of anionic dyes with polyaniline implanted cellulose: organic $\pi$-conjugated macromolecules in environmental applications. J Mol Liq 261:189-198

Bhowmik M, Deb K, Debnath A, Saha B (2018b) Mixed phase $\mathrm{Fe}_{2} \mathrm{O}_{3} / \mathrm{Mn}_{3} \mathrm{O}_{4}$ magnetic nanocomposite for enhanced adsorption of methyl orange dye: neural network modeling and response surface methodology optimization. Appl Organomet Chem 32(3):e4186

Deb K, Kanmani M, Debnath A, Bhowmik KL, Saha B (2019) Ultrasonic assisted enhanced adsorption of methyl orange dye onto polyaniline impregnated zinc oxide nanoparticles: kinetic, isotherm and optimization of process parameters. Ultrason Sonochem 54:290-301

Doke KM, Yusufi M, Joseph RD, Khan EM (2012) Bio-sorption of hexavalent chromium onto wood apple shell: equilibrium, kinetic and thermodynamic studies. Desalin Water Treat 50:170-197

Duan J, Lu Q, Chen R, Duan Y, Wang L, Gao L, Pan S (2010) Synthesis of a novel flocculant on the basis of crosslinked Konjac glucomannan-graft-polyacrylamide-co-sodium xanthate and its application in removal of $\mathrm{Cu}^{2+}$ ion. Carbohyd Polym 80(2):436-441
Faisal AAH, Ahmed MD (2014) Remediation of groundwater contaminated with copper ions by waste foundry sand permeable barrier. J Eng 20:62-77

Faisal AAH, Hmood ZA (2015) Groundwater protection from cadmium contamination by zeolite permeable reactive barrier. Desalin Water Treat 53:1377-1386

Foo K, Hameed B (2010) Insights into the modeling of adsorption isotherm systems. Chem Eng J 156(1):2-10

Frid P, Anisimov SV, Popovic N (2007) Congo Red and protein aggregation in neurodegenerative diseases. Brain Res Rev 53(1): $135-160$

Gheju M, Miulescu A (2007) Sorption equilibrium of hexavalent chromium on granular activated carbon. Chem Bull POLITEHNICA Univ Timis 52(66):41-46

Golka K, Kopps S, Myslak ZW (2004) Carcinogenicity of azo colorants: influence of solubility and bioavailability. Toxicol Lett 151(1):203-210

Gopinathan R, Kanhere J, Banerjee J (2015) Effect of malachite green toxicity on non target soil organisms. Chemosphere 120:637-644

Gürses A, Doğar C, Yalçın M, Açıkyıldız M, Bayrak R, Karaca S (2006) The adsorption kinetics of the cationic dye, methylene blue, onto clay. J Hazard Mater 131(1-3):217-228

Hamdaoui O, Naffrechoux E (2007) Modeling of adsorption isotherms of phenol and chlorophenols onto granular activated carbon part I. Two-parameter models and equations allowing determination of thermodynamic parameters. J Hazard Mater 147(1-2):381-394

Ho YS, McKay G (1999) Pseudo-second order model for sorption processes. Process Biochem 34(5):451-465

Ho YS, Porter JF, McKay G (2002) Equilibrium isotherm studies for the sorption of divalent metal ions onto peat: Copper, nickel and lead single component systems. Water Air Soil Pollut 141(1-4):1-33

Jiang M, Jin X, Lu X-Q, Chen Z (2010) Adsorption of Pb(II), Cd(II), $\mathrm{Ni}(\mathrm{II})$ and $\mathrm{Cu}(\mathrm{II})$ onto natural kaolinite clay. Desalination 252(1-3):33-39

Kim U-J, Kimura S, Wada M (2019) Highly enhanced adsorption of Congo Red onto dialdehyde cellulose-crosslinked cellulose-chitosan foam. Carbohyd Polym 214:294-302

Lagergren S (1989) About the theory of so-called adsorption of soluble substances. Kungliga Svenska Vetenskapsakademiens Handlingar 24(4): $1-39$

Mathews AP, Zayas I (1989) Particle size and shape effects on adsorption rate parameters. J Environ Eng 115(1):41-55

Mironyuk I, Tatarchuk T, Naushad M, Vasylyeva H, Mykytyn I (2019) Highly efficient adsorption of strontium ions by carbonated mesoporous $\mathrm{TiO}_{2}$. J Mol Liq 285:742-753

Namasivayam C, Kavitha D (2002) Removal of Congo Red from water by adsorption onto activated carbon prepared from coir pith, an agricultural solid waste. Dye Pigment 54:47-58. https://doi. org/10.1016/S0143-7208(02)00025-6

Naushad M, ALOthman ZA (2015) Separation of toxic $\mathrm{Pb} 2^{+}$metal from aqueous solution using strongly acidic cation-exchange resin: analytical applications for the removal of metal ions from pharmaceutical formulation. Desalin Water Treat 53:2158-2166. https://doi.org/10.1080/19443994.2013.862744

Naushad M, Mittal A, Rathore M, Gupta V (2015) Ion-exchange kinetic studies for $\mathrm{Cd}(\mathrm{II}), \mathrm{Co}(\mathrm{II}), \mathrm{Cu}(\mathrm{II})$, and $\mathrm{Pb}(\mathrm{II})$ metal ions over a composite cation exchanger. Desalin Water Treat 54:2883-2890

Naushad M, Vasudevan S, Sharma G, Kumar A, Alothman ZA (2016a) Adsorption kinetics, isotherms, and thermodynamic studies for $\mathrm{Hg}_{2}{ }^{+}$adsorption from aqueous medium using alizarin red-S-loaded amberlite IRA-400 resin. Desalin Water Treat 57:18551-18559

Naushad M, ALOthman ZA, Awual MR et al (2016b) Adsorption of rose Bengal dye from aqueous solution by amberlite Ira-938 resin: 
kinetics, isotherms, and thermodynamic studies. Desalin Water Treat 57:13527-13533

Naushad M, Sharma G, Alothman ZA (2019) Photodegradation of toxic dye using Gum Arabic-crosslinked-poly(acrylamide)/ $\mathrm{Ni}(\mathrm{OH})_{2} /$ FeOOH nanocomposites hydrogel. J Clean Prod 241:118263

Phuengprasop T, Sittiwong J, Unob F (2011) Removal of heavy metal ions by iron oxide coated sewage sludge. J Hazard Mater 186(1):502-507

Puranik PR, Modak JM, Paknikar KM (1999) A comparative study of the mass transfer kinetics of metal biosorption by microbial biomass. Hydrometallurgy 52(2):189-197

Rashid HM, Faisal AAH (2019) Removal of dissolved trivalent chromium ions from contaminated wastewater using locally available raw scrap iron-aluminum waste. Al-Khwarizmi Eng J 15:134-143

Safarik I, Rego LFT, Borovska M (2007) New magnetically responsive yeast-based biosorbent for the efficient removal of water-soluble dyes. Enzyme Microbial Technol 40(6):1551-1556

Sahoo JK, Kumar A, Rath J, Mohanty T, Dash P, Sahoo H (2017) Guar gum-coated iron oxide nanocomposite as an efficient adsorbent for Congo Red dye. Desalin Water Treat 95:342-354

Sahoo JK, Paikra SK, Mishra M, Sahoo H (2019) Amine functionalized magnetic iron oxide nanoparticles: synthesis, antibacterial activity and rapid removal of Congo Red dye. J Mol Liq 282(15):428-440

Sarkar K, Deb K, Debnath A, Bera A, Debnath A, Saha B (2018) Polaron localization in polyaniline through methylene blue dye interaction for tuned charge transport and optical properties. Colloid Polym Sci 296(12):1927-1934. https://doi.org/10.1007/s0039 6-018-4419-3

Simantiraki F, Kollias CG, Maratos D, Hahladakis J, Gidarakos E (2013) Qualitative determination and application of sewage sludge and municipal solid waste compost for BTEX removal from groundwater. J Environ Chem Eng 1:9-17
Sonal S, Singh A, Mishra BK (2018) Decolorization of reactive dye remazol brilliant blue $\mathrm{R}$ by zirconium oxychloride as a novel coagulant: optimization through response surface methodology. Water Sci Technol 78(2):379-389

Tatarchuk T, Paliychuk N, Bitra RB, Shyichuk A, Naushad M, Mironyuk I, Ziółkowska D (2019) Adsorptive removal of toxic Methylene Blue and Acid Orange 7 dyes from aqueous medium using cobalt-zinc ferrite nanoadsorbents. Desalin Water Treat 150:374-385

Wang L, Wang A (2007) Adsorption characteristics of Congo Red onto the chitosan/montmorillonite nanocomposite. J Hazard Mater 147(3):979-985

Yang S, Wang L, Zhang X, Yang W, Song G (2015) Enhanced adsorption of Congo Red dye by functionalized carbon nanotube/mixed metal oxides nanocomposites derived from layered double hydroxide precursor. Chem Engineerinf J 275:315-321

Zhao J, Lu Z, He X, Zhang X, Li Q, Xia T, Zhang W, Lu C (2017) Fabrication and characterization of highly porous $\mathrm{Fe}(\mathrm{OH})_{3} @$ cellulose hybrid fibers for effective removal of Congo Red from contaminated water. ACS Sustain Chem Eng 5(9):7723-7732

Zheng H, Liu D, Zheng Y, Liang S, Liu Z (2009) Sorption isotherm and kinetic modeling of aniline on Cr-bentonite. J Hazard Mater 167(1-3):141-147

Zheng Y, Zhu B, Chen H, You W, Jiang C, Yu J (2017) Hierarchical flower-like nickel(II) oxide microspheres with high adsorption capacity of Congo Red in water. J Colloid Interface Sci 504:688-696

Zheng Y, Cheng B, You W, Yu J, Ho W (2019) 3D hierarchical graphene oxide-NiFe LDH composite with enhanced adsorption affinity to Congo Red, methyl orange and $\mathrm{Cr}(\mathrm{VI})$ ions. J Hazard Mater 369:214-225

\section{Affiliations}

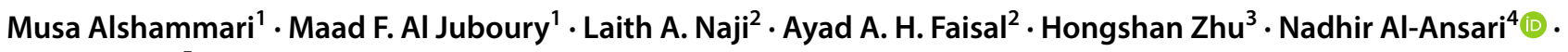 Mu Naushad ${ }^{5}$}

Musa Alshammari

drmuhabib@uokerbala.edu.iq

Maad F. Al Juboury

maad.farooq@uokerbala.edu.iq

Laith A. Naji

add.ali.lith@gmail.com

Ayad A. H. Faisal

ayadabedalhamzafaisal@yahoo.com

Hongshan Zhu

hszhu@mail.ustc.edu.cn

Mu Naushad

mnaushad@ksu.edu.sa
1 College of Engineering, University of Kerbala, Karbala, Iraq

2 Department of Environmental Engineering, College of Engineering, University of Baghdad, Baghdad, Iraq

3 Institute of Plasma Physics, Chinese Academy of Sciences, Shushanhu Road 350, Shushan District, Hefei 230031, P.R. China

4 Department of Civil, Environmental and Natural Resources Engineering, Lulea University of Technology, Lulea, Sweden

5 King Saud University, Riyadh 11451, Saudi Arabia 